\title{
3 Research Square

\section{Evaluation of a cell-based osteogenic formulation compliant with good manufacturing practice for use in tissue engineering}

\section{Daniel Vivas}

Banc de Sang i Teixits

Marta Grau-Vorster

Banc de Sang i Teixits

Irene Oliver-Vila

Banc de Sang i Teixits

Joan García-López

Banc de Sang i Teixits

Joaquim Vives ( $\nabla$ jvives@bst.cat )

Banc de Sang i Teixits https://orcid.org/0000-0001-9719-5235

\section{Research}

Keywords: Multipotent Mesenchymal Stromal Cell, Good Manufacturing Practice, hydrogel, bone remodelling, cell therapy, Cell culture, tissue engineering

Posted Date: February 26th, 2020

DOI: https://doi.org/10.21203/rs.2.24551/v1

License: (c) (i) This work is licensed under a Creative Commons Attribution 4.0 International License.

Read Full License

Version of Record: A version of this preprint was published at Molecular Biology Reports on June 19th, 2020. See the published version at https://doi.org/10.1007/s11033-020-05588-z. 


\section{Abstract}

Background Proper bony tissue regeneration requires mechanical stabilization, an osteogenic biological activity and appropriate scaffolds. The latter two elements can be combined in a hydrogel format for effective delivery, so it can readily adapt to the architecture of the defect.

Results We evaluated a Good Manufacturing Practice-compliant formulation composed of bone marrowderived mesenchymal stromal cells in combination with bone particles $(\varnothing=0.25$ to $1 \mu \mathrm{m})$ and fibrin, which can be readily translated into the clinical setting for the treatment of bone defects, as an alternative to bone tissue autografts. Remarkably, cells survived with unaltered phenotype (CD73 + , CD $90+, C D 105$ ,+ CD31 - , CD 45 - ) and retained their osteogenic capacity up to $48 \mathrm{~h}$ after being combined with hydrogel and bone particles, thus demonstrating the stability of their identity and potency. Moreover, in a subchronic toxicity in vivo study, no toxicity was observed upon subcutaneous administration in athymic mice and signs of osteogenesis and vascularization were detected two months after administration.

Conclusions The preclinical data gathered in the present work, in compliance with current quality and regulatory requirements, demonstrated the feasibility of formulating an osteogenic cell-based tissue engineering product with a defined profile including identity, purity and potency (in vitro and in vivo ), which is required prior to move towards its use of prior to its clinical use.

\section{Background}

Failure of the physiologic reaction to acute or chronic bone disorders (e.g. fractures, non-unions, large defects after trauma or tumors) typically requires surgical intervention and implantation of bone grafts. Autografts and heterologous transplants of bony tissue, as well as the use of implants made of biomaterials, are the most common approaches in today's orthopedics field (1). Among them, the bony autograft sourced from the iliac crest is the preferred treatment option for a wide range of orthopedic conditions, including the management of complex fractures or in non-union defects $(1,2)$. The use of autologous tissue as a vector for bony regeneration fulfils three key requirements: 1 ) introduces cells with osteogenic potential, 2) offers structural support (osteoconduction), and 3) contributes with growth factors that promote vascularization and osteoinduction (1). However, the complete substitution of the damaged bony tissue is not always achieved through the use of autografts, which can lead to the failure of the autograft at long term (3). On the other hand, the surgical collection of autologous bone is highly associated with morbidity (4), which in some cases can be overcome by using allogeneic, decellularized human bone from tissue banks. However, such strategy lacks the benefits associated to the regenerating activity displayed by osteogenic cells, which have been demonstrated to be a key factor in our hands, after its successful use in animal models and clinical cases $(5,6)$, in accordance with the "diamond concept" (1). In fact, autografts are preferred for treating large bony defects even when bony tissue from tissue bank is available. Unfortunately, this option is not valid for all patients and it is not exempt of risks of the procedure required for tissue extraction, as discussed previously. Therefore, when this approach is not feasible (i.e. re-interventions, donor site morbidity, infections), the use of osteogenic cells isolated 
from bone marrow (BM), either as bulk concentrates or enriched in multipotent mesenchymal stromal cells by ex vivo expansion, is an alternative that has already been explored in large animal models, and also in early Phase I/II clinical trials with encouraging results (5-8). It is particularly interesting the development of products that combine culture-expanded multipotent Mesenchymal Stromal Cells (MSC) and scaffolds, namely "Tissue Engineering Products" (TEP), resulting in a new medicinal entity with osteogenic potential that is specifically regulated as advanced therapy and needs to comply with pharmaceutical regulations (9).

In the present study, we formulated TEP based on the use of cells with osteogenic potential (namely, ex vivo expanded MSC that were compared to BM concentrates) combined with bony particles from tissue bank embedded in a hydrogel that, altogether, can induce the generation of new tissue while adapting to the diverse architecture of the simulated cylindrical bony defects. In agreement with current quality and regulatory requirements, TEP's stability, osteogenic potential and in vivo safety were assessed comprehensively under Good Laboratory and Manufacturing Practices.

\section{Material And Methods}

\section{Cell cultures}

Clinical grade ex vivo expanded MSC derived from the mononuclear cell (MNC) fraction of BM aspirates were produced in the context of a clinical trial (EudraCT No. 2010-024041-78) with appropriate donor informed consent. Cells were further expanded in vitro up to sufficient numbers (always under passage 4) by using Dulbecco's Modified Eagle's Medium (DMEM; Gibco) containing 2 mM glutamine supplemented with $10 \%$ human serum (hSer) $\mathrm{B} / \mathrm{AB}(10,11)$. All cultures were maintained at $37^{\circ} \mathrm{C}$ and $5 \% \mathrm{CO}_{2}$ in humidified incubators. Cell number and viability were determined by either the hemocytometer-based Trypan blue dye exclusion method or by using ViaCount Reagent and analysis in a Guava EasyCyte Mini device following the manufacturer's instructions (EMD; Millipore, Billerica, MA, USA).

\section{Differentiation assays}

Specific differentiation media (StemPro; Gibco) were used for the adipogenic, chondrogenic and osteogenic induction of undifferentiated MSC cultures in vitro. Oil Red O (Sigma), Safranin O (Sigma) and Alkaline Phosphatase (Takara Bio Inc.) stainings were performed for the determination of the outcome of the differentiation assays as described elsewhere (12).

\section{Stability assessment}

The effect of fibrinogen on BM-MSCs' stability was assessed by means of analyzing cell viability, phenotype, capacity to adhere to plastic surfaces and osteogenic differentiation capacity at $2-8{ }^{\circ} \mathrm{C}$ with freshly prepared cellular suspensions (13).

\section{Cell Proliferation Assay}


Cell proliferation was monitored by using the ATP-based CellTiter-Glo® Luminescent Cell Viability Assay (Promega, Madison WI, USA) following the vendor's instructions. Briefly, cells were cultured in multiwell format plates and, at the time of analysis, luminescent reagent was added to each well at 1:1 (v/v) ratio with respect to culture medium and shook for 2 min using an orbital shaker. After 15 min incubation in the dark, $100 \mu \mathrm{L}$ of supernatant from each well were transferred into opaque-walled 96 well-plates and their luminescence was measured in triplicates on a Triad Multimode detector plate reader (Dynex Technologies, Chantilly, VI).

\section{Flow cytometry}

Fluorescence-Activated Cell Sorting (FACS) analysis was performed to evaluate expression of surface markers CD31 (WM59, BD Biosciences), CD45 (HI30, BD Biosciences), CD73 (AD2, BD Biosciences), CD90 (5E10, BD Biosciences), CD105 (43A4E1, Miltenyi Biotec) and HLA-DR (TU36, BD Biosciences) in a FACSCalibur device (Becton Dickinson).

\section{Preparation of osteogenic tissue engineering product}

Osteogenic hydrogels were prepared following a Good Manufacturing Practice compliant procedure. Briefly, a cellular pellet was obtained and then resuspended in a volume of saline solution supplemented with $2 \%(\mathrm{w} / \mathrm{v})$ of human serum albumin (HSA; Albutein ${ }^{\circledR}$, Grifols). Then the same volume of fibrinogen (Tissucol Duo, Baxter) was added. This mixture was combined with cadaveric, particulated, decellularized and deantigenized bone from tissue bank approved for human use (diameter of particles comprised between 0.25-1 mm) and commercial thrombin (Tissucol Duo, Baxter) diluted 1:100 in saline solution (final concentration $50 \mathrm{Ul} / \mathrm{mL}$ ).

\section{Animals}

Eighteen healthy 7 to 8 weeks old Crl:NIH-Foxn $1^{\text {rnu }}$ female mice (Charles River Laboratories, France) were randomly distributed at a maximum of 3 animals per cage according to the assigned experimental group (namely, acellular control, MNC-loaded TEP, and MSC-loaded TEP), after a 7-day acclimatization period in autonomous pressurized units. Animals were housed together in Specific Pathogen Free (SPF) facilities, fed a standard diet and allowed access to water ad libitum. All animal care and experimental procedures adhered to the recommendations of local, national, and European laws (Decret 214 de 1997, Real Decreto 53 de 2013, European directive 86/609/CEE of 1986, respectively) and were approved by the Universitat Autònoma de Barcelona's Ethical Committee on Human and Animal Experimentation (Ref. No. CEAAH 1972), and registered by Generalitat de Catalunya (Reg. No. DMAiH 6967). This study was performed under Good Laboratory Practices and inspected by our institutional Quality Assurance Unit and verified by the competent authority. The athymic mouse strain Crl:NIH-Foxn $1^{\text {rnu }}(14,15)$ was chosen in this study for carrying a mutation in the rnu locus in chromosome 10 resulting in a deficiency of functional $T$ lymphocytes, a characteristic required for the heterologous transplantation of human biologic material (15-17).

\section{Experimental surgery}


Animals were induced with inhalatory anesthesia consisting of $4 \%$ isofluorane mixed with $100 \%$ oxygen in an anesthetic chamber. Anaesthetized animals were placed on a heating blanket and maintained on isoflurane $2 \%$ mixed with $100 \%$ oxygen administered through an anesthetic mask. Two $\mathrm{mg} / \mathrm{kg}$ meloxicam were administered subcutaneously for analgesia, and ophthalmic lubricant was placed on the eyes in order to prevent eyes dryness. The surgical zone was sterilized and a $1 \mathrm{~cm}$ long incision was made in the epidermis of the dorsal zone, caudal to the shoulder blade and perpendicular to the spinal column. In order to perform the incision, the skin was pinched and pulled using blunt-ended surgical forceps and incised with straight-bladed Mayo scissors. Then, the subcutaneous area was dissected cranially to the incision forming a pouch where the test and reference items were placed using curved Adson forceps. After implantation, the surgical wound was closed with two surgical staples and the animals were maintained on the heating blanket until total recovery before returning them to the original cage (Supplemental Fig. 1).

\section{Necropsy and histology}

At the end of the two-month follow-up period, animals were euthanized by an overdose of sodium pentobarbital (200 mg/kg, $60 \mathrm{mg} / \mathrm{mL})$ administered intraperitoneally. The macroscopic analysis included the assessment of the musculature, fur, skin and natural orifices. Additionally, the brain and cranium, thoracic cavity and mediastinum, trachea, esophagus, glands and lymph nodes, lungs, heart, abdominal cavity including stomach, small and large intestine, liver, spleen, kidneys and genitourinary system were examined. All these organs were then extracted, minced, fixed and embedded in paraffin for further histological studies. Two $\mu \mathrm{m}$ thick microtome sections of the specimens were cut in the sagittal plane and examined by routine hematoxylin and eosin (H\&E) staining using a grading score specific for the assessment of bone formation (Supplemental Table 1).

\section{Data analysis}

Descriptive data was expressed as mean \pm standard deviation (number of replicates) or mean (range of values). One-way ANOVA test and Bonferroni's multiple comparison tests were performed to evaluate differences in water and food consumption, body weight gain. Paired t-tests were performed to evaluate differences in size and histological scores. Statistical significance was set at * $p<0.05$.

\section{Results}

\section{Sourcing of cells, characterization and formulation of an osteogenic hydrogel}

First, cells isolated from BM aspirates were successfully expanded in culture up to sufficient numbers for use in the series of in vitro and in vivo experiments described next. Phenotypic profiles of BM-derived MSC (BM-MSC) were consistent with their mesenchymal identity, being positive for the expression of CD90, CD73, CD105; negative for CD31 and CD45; and slightly positive for HLA-DR (Figure 1A). In vitro 
differentiation assays confirmed the multipotentiality of culture expanded BM-MSC into the adipogenic, chondrogenic and osteogenic lineages (Figure 1B).

The osteogenic formulation studied here was composed of A) a cellular component made of cells resuspended in saline solution and fibrinogen at 1:1 (v/v); and B) an acellular component made of bony particles and $1 \%(\mathrm{v} / \mathrm{v})$ diluted thrombin to avoid immediate polymerization of fibrin. Provided that current clinical practice employs bone marrow concentrates as source of osteogenic cells in several indications, we decided to include an additional formulation with MNC as comparator for BM-MSC in animal studies.

\section{MSC embedded in fibrinogen survived and maintained their phenotype and osteogenic potential}

The effect of fibrinogen on cellular stability was investigated by assessing cell viability, which remained stable up to 48 hours at $2-8{ }^{\circ} \mathrm{C}$ (Figure $2 \mathrm{~A}$ ). Phenotype at $24 \mathrm{~h}$ was consistent with initial MSC identity determined at the start of the experiment (Figure 2B). In order to understand whether cells retained their capacity to adhere to plastic surfaces along the course of the study, as a surrogate marker of cell viability, we evaluated this parameter at $0,6,18,24$ and $48 \mathrm{~h}$ to complement cytometric data. Interestingly, cells were viable along the study time and no gross differences were observed regarding the morphology of adherent cells during the first 24 hours (Figure 2C). However, at $48 \mathrm{~h}$, most of the cells stayed in the supernatant and did not display the capacity to adhere to cell-culture treated plastic surfaces. Despite the presence of fibrinogen for 24 hours, incubation of BM-MSC in osteogenic medium for 8 days resulted in readily differentiation into osteoblasts as revealed by positive ALP staining (Figure 2D).

\section{Preparation of constructs}

First, a pellet of cells was obtained and then resuspended in a volume of saline solution supplemented with $2 \%(\mathrm{w} / \mathrm{v})$ of human albumin and fibrinogen at 1:1 (v/v) with a final concentration of fibrinogen in the range of $35-55 \mathrm{mg} / \mathrm{mL}$. This mixture was combined with cadaveric, particulated, decellularized and deantigenized bone from tissue bank (diameter of particles comprised between 0.25-1 mm) and thrombin diluted 1:100 (v/v) in saline solution resulting in a final concentration of $5 \mathrm{Ul} / \mathrm{mL}$. We tested this formulation in $1 \mathrm{~mL}$ syringes whose edges were previously cut, with the aim of simulating a cylindrical bone defect (Supplemental Figure 1C). Under such conditions, the jelly mixture clotted within minutes while adapting perfectly its shape to the cylindrical shape.

Next we generated cylindrical constructs as a model experimental situation of cylindrical defect, using three formulations: acellular (control group), MNC-loaded and MSC-loaded TEPs. The cellular doses were $48 \times 10^{7} \mathrm{MNC} / \mathrm{cm}^{3}$ of bone and $60 \times 10^{6} \mathrm{MSC} / \mathrm{cm}^{3}$ of bone (Figure $3 \mathrm{~A}$ ). Those cylinders were cut in a way that $0.2 \mathrm{~cm}^{3}$ constructs were obtained for the following in vivo verification of their safety and osteogenic and angiogenic capacity. 


\section{In vivo experiments demonstrating vascularization and osteogenesis}

In addition to in vitro analyses, in vivo studies were performed to demonstrate safety and efficacy of the osteogenic formulation reported here. Constructs of $0.2 \mathrm{~cm}^{3}$ were implanted subcutaneously between the scapulae of athymic mice and they were followed up for 2 months. All animals survived the surgery without any adverse reactions to the procedure. Several clinical parameters were monitored throughout the study (including weight, general condition, wound appearance, food and water intake). The surgical wound healed normally in all animals, which presented a healthy general condition throughout the experimental phase. No spontaneous mortality occurred in the course of the study, nor was any pathological condition observed. All animals increased in body weight throughout the study, only a slight decrease in the body weight gain immediately after administration of the constructs was observed, which can be attributed to animal handling and surgery (Figure 3B). A full necropsy at termination was performed to all animals and only unspecific findings were observed in all three experimental groups, irrespective of treatment, which were not considered to have pathologic relevance thus confirming the lack of toxicity (Supplemental Figure 2). In addition, no signs of rejection of the implants were observed macroscopically.

In the control group, the constructs were absorbed gradually until becoming unnoticeable macroscopically (with the exception of one animal, as shown in Supplemental Figure 3 at week 5). In the groups treated with cell-based TEPs, a reduction of the initial size of the constructs was observed although they increased gradually thereafter reaching a peak of growth at five weeks after surgery and further shrunk until the euthanasia at week 8 . At termination, the dimensions of the constructs varied between experimental groups $\left(\varnothing=1 \pm 2.4,6.8 \pm 6.1\right.$ and $12 \pm 10.0 \mathrm{~mm}^{2}$ for control, MNC and BM-MSC, respectively), being MSC-loaded TEP the one showing a significantly higher size increase compared to the control group $(p=0.0191)$ (Figure 3C). Interestingly, the presence of MSC prevented the fragmentation of the test item that remained in one single piece along the course of the study, whilst multifocal fragmented particles were observed in some animals from the group treated with MNC (Supplemental Figure 2). Despite the evident increased size of new tissue in the BM-MSC treated group, differences in

the overall histological scores were non-significant in all cases although highest values were observed in the animals treated with BM-MSC $(6.1 \pm 1.7,5.9 \pm 1,8$, and $7.7 \pm 1.3$, for control, MNC- and BM-MSCloaded TEPs, respectively) (Table 1). Remarkably a statistically significant increment of vascularization was observed in the BM-MSC-treated group compared to both control $(2.6 \pm 0.5$ vs $0.75 \pm 1.0 ; p=0.0650)$ and MNC-treated animals ( $2.6 \pm 0.5$ vs $1.2 \pm 0.8 ; p=0.0285$ ). Although no evident osteoblastic lines were found, which may have indicated the formation of secondary bone substance associated to the bone particles, there was a sign of osteogenesis in all experimental groups (Figure 3D). 
Table 1

Summary of histological scores. MNC: Mononuclear cells from bone marrow aspirate; BM-MSC: Bone Marrow-derived multipotent Mesenchymal Stromal Cells.

\begin{tabular}{|llll|}
\hline \multirow{2}{*}{ Category } & \multicolumn{2}{l}{ Score } & \\
\cline { 2 - 4 } & Acellular control & MNC & BM-MSC \\
\hline Bone formation & $0.8 \pm 1.0$ & $0.8 \pm 0.8$ & 1.0 \\
\hline Tissue reaction & $1.6 \pm 0.5$ & $1.5 \pm 1.1$ & $1.3 \pm 0.8$ \\
\hline Inflammatory reaction & 2.0 & $1.4 \pm 0.5$ & $1.8 \pm 0.4$ \\
\hline Inflammatory cell type & 1.0 & 1.0 & 1.0 \\
\hline Vascularisation around bone particles & $0.8 \pm 1.0$ & $2.6 \pm 0.5$ & $1.2 \pm 0.8$ \\
\hline SUPPLEMENTAL TABLES & & & \\
\hline $\begin{array}{l}\text { SUPPLEMENTAL TABLE 1. Histological grading score. Parameters related to bone formation were } \\
\text { assessed under 5 different categories. }\end{array}$ & & \\
\hline
\end{tabular}

\section{Discussion}

Treatment of bone defects using osteogenic cell-laden hydrogels that can adapt to the architecture of the lesion might soon become a useful tool for orthopedic surgeons (18). In the present study, we explored whether BM-MSC expanded under a Good Manufacturing Practice (GMP)-compliant production process preserved their viability, identity and osteogenic potential when combined with commercial fibrin and decellularized/deantigenized bone particles sourced from tissue bank as a TEP. We found that indeed cells remained viable and preserved their osteogenic capacity in such osteogenic formulation, so it could be potentially used in the treatment of a wide range of orthopedic conditions or even as bioink in 3D bioprinting strategies $(19,20)$. Regarding the phenotype, although HLA-DR expression was higher than the criteria established by the International Society for Cell and Gene Therapy (ISCT) (21), it did comply with product specifications that were approved by the competent authority (11). Indeed, varying percentages of HLA-DR expression are often reported in MSC cultures, despite meeting the rest of defining criteria (22-26).

In current clinical practice, the use of BM concentrates are becoming popular in an attempt to provide stem cells to the fracture site. Although BM aspirates are typically processed in order to isolate the MNC fraction, this is not composed only of MSC but a heterogeneous population of B-cells, T-cells and monocytes, as well as rare progenitor cell types such as hematopoietic stem progenitor cells (HPCs) and endothelial progenitor cells (EPCs), it is still unclear which component or combination of components exactly determines its tissue induction activity, which can be exerted either by direct differentiation or by paracrine activity. It has been previously described that the MNC fraction from BM can promote angiogenesis (27), mediate vascular repair, produce cytoprotective growth factors and cytokines (28), and 
regenerate bone (29). From all the different subpopulations present in the bone marrow, MSC contribute to a very small fraction, estimated in the range from $0.001-0.1 \%$ of $\operatorname{MNC}(30,31)$. Despite of such low occurrence, BM-MSC can be efficiently expanded ex vivo and induced to differentiate into multiple lineages when subjected to defined culture conditions (29). In the orthopedics field, the use of pure populations of MSC is thought to promote bone formation more efficiently.

In the present study we employed fibrin hydrogel as a clotting agent, which is a commercially available product for clinical use that can also be manufactured in situ on demand either as allogeneic or autologous product $(32,33)$. Typically, fibrin is presented in a formulation of two components: A) concentrate or purified fibrinogen, which is the precursor glycoprotein of fibrin, and B) a mixture of factor $\mathrm{XIII}$, thrombin and calcium, which triggers the polymerization reaction (32). In fact, fibrin glue is a widely known product in the surgery field that is used for rapid hemostasis (34), acceleration of wound healing (35), reduction of blood loss (36), protection against bacterial infections (37) and its capacity for shaping to the architecture of the application zone (6). Since human fibrin is highly biocompatible and resorbable, it can be used as a vehicle for bioactive ingredients in tissue engineering strategies (33). Remarkably, MSC maintained their features and viability, when combined with fibrinogen. Such biocompatibility was key in the outcome observed after administration into animals, in which new tissue formation may result from either direct differentiation to osteogenic cells or paracrine activity, which is known to exert a "calling" signaling effect both locally and systemically, or as a result of the combination of both mechanisms (38). Our results are in the same line as those obtained by Seebach and collaborators, who demonstrated the compatibility of fibrin with MSC and obtained similar results regarding the angiogenic activity in a study inducing bone healing in rats (39).

Both fibrin gels and bony particles used as scaffolds in the present study displayed key features as a support for the repair of damaged bone tissue, providing a jelly texture that allows for the spatial localization of the cellular component with osteogenic potential, therefore adapting itself to the morphology of the fracture site. Particulated decellularized/deantigenized bone matrix from human cadaveric donors can be found commercially on different size formats. Small particles, like we employed in the present study, make possible to increase the surface area so, their natural osteoinductive and osteoconductive properties are available to cells embedded in fibrin hydrogels (5). The non-cellular components of the TEPs have the capacity to generate a biological environment that ensures the supply of nutrients to the cells and facilitates their regenerative function. Remarkably, both acellular and cellladen osteogenic formulations showed osteogenic properties in vivo being BM-MSC-loaded TEP clearly the most potent formulation for generating extensive bone-like tissue and inducing improved vascularization. These findings are in accordance with similar studies published by Yamada and collaborators demonstrating bone regenerative activity when applying MSC-based TEP in a canine preclinical model first, and in the clinical setting afterwards (40-42). Kargozar and collaborators also reported a comparative study in rats with positive results regarding bone regeneration in the case of BMMSC-based TEP (43). Despite of the promising outcomes of the present study, similar TEPs based in cell aggregates or cell sheets are gaining ground among the regenerative medicine field suggesting that 
different delivery modes of the active ingredient within the TEP may enhance tissue regeneration and therefore much effort is currently being made in order to improve such formulations $(44,45)$.

\section{Conclusions}

The present study provides evidence of the feasibility of TEP preparation with clinical-grade reagents while preserving the identity, osteogenic potency and safety of cells used in its formulation. Moreover, the preclinical data gathered in the present work, in compliance with current quality and regulatory requirements, are fundamental for subsequent translation into the clinical setting.

\section{Abbreviations}

ALP

Alkaline phosphatase

BM

Bone Marrow

DMEM

Dulbecco's Modified Eagle's Medium

EPC

endothelial progenitor cells

GMP

Good Manufacturing Practice

HLA

Human Leukocyte Antigen

HPC

hematopoietic stem progenitor cells

HSA

human serum albumin

MNC

Mononuclear cell

MSC

Multipotent Mesenchymal Stromal Cells

$\mathrm{P}$

Passage number

PBMC

Peripheral Blood Mononuclear Cells

TEP

Tissue Engineering Product

\section{Declarations}


Ethics approval and consent to participate: cells were sourced from Banc de Sang i Teixits' Biobank (Barcelona, Spain) and had appropriate donor informed consent for use in research. Authorization issued by Hospital de la Vall d'Hebron's Ethics Committee (Barcelona, Spain) to JV. All animal care and experimental procedures adhered to the recommendations of local, national, and European laws (Decret 214 de 1997, Real Decreto 53 de 2013, European directive 86/609/CEE of 1986, respectively) and were approved by the Universitat Autònoma de Barcelona's Ethical Committee on Human and Animal Experimentation (Ref. No. CEAAH 1972), and registered by Generalitat de Catalunya (Reg. No. DMAiH 6967).

Consent for publication: Not applicable.

Availability of data and material: All datasets generated for this study are included in the manuscript and the supplementary files.

Competing interests: No competing interests to declare.

Funding: This work has been developed in the context of ADVANCE(CAT) with the support of ACCIÓ (Catalonia Trade \& Investment; Generalitat de Catalunya) and the European Community under the Catalonian ERDF operational program (European Regional Development Fund) 2014-2020, Generalitat de Catalunya (Departament de Salut) PERIS Acció Instrumental de Programes de Recerca Orientats (SLT002/16/00234) and by the Spanish Cell Therapy Network (TerCel, expedient number: RD16/0011/0028). Project PI19/01788 is funded by Instituto de Salud Carlos III and co-funded by European Union (ERDF/ESF) - A way to build Europe. JV's laboratory is awarded by the Generalitat de Catalunya as Consolidated Research Group (ref. 2017SGR719).

Authors' contributions: DV, MG-V, IOV and JV performed experiments and analysed data; JG-L and JV conceived the study; DV and JV revised data and wrote the manuscript. All authors revised and approved the final version of the manuscript.

Acknowledgements: The authors would like to acknowledge former members of Xcelia and current members of Servei de Teràpia Cel·lular (Banc de Sang i Teixits, Barcelona) for technical support and advice.

\section{References}

1. Giannoudis PV, Einhorn TA, Marsh D. Fracture healing: the diamond concept. Injury. 2007;38 Suppl 4:S3-6.

2. Dias MI, Lourenco P, Rodrigues A, Azevedo J, Viegas C, Ferreira A, et al. [The effect of the quantitative variation of autologous spongy bone graft applied for bone regeneration in an experimental model of tibia osteotomy]. Acta Med Port. 2007;20(1):37-46.

3. Wheeler DL, Enneking WF. Allograft bone decreases in strength in vivo over time. Clin Orthop Relat Res. 2005(435):36-42. 
4. Chou LB, Mann RA, Coughlin MJ, McPeake WT, 3rd, Mizel MS. Stress fracture as a complication of autogenous bone graft harvest from the distal tibia. Foot Ankle Int. 2007;28(2):199-201.

5. Prat S, Gallardo-Villares S, Vives M, Carreño A, Caminal M, Oliver-Vila I, et al. Clinical translation of a mesenchymal stromal cell-based therapy developed in a large animal model and two case studies of the treatment of atrophic pseudoarthrosis. Journal of Tissue Engineering and Regenerative Medicine. 2018;12(1):e532-e40.

6. Caminal M, Velez R, Rabanal RM, Vivas D, Batlle-Morera L, Aguirre M, et al. A reproducible method for the isolation and expansion of ovine mesenchymal stromal cells from bone marrow for use in regenerative medicine preclinical studies. J Tissue Eng Regen Med. 2017;11(12):3408-16.

7. Hernigou P, Poignard A, Beaujean F, Rouard H. Percutaneous autologous bone-marrow grafting for nonunions. Influence of the number and concentration of progenitor cells. J Bone Joint Surg Am. 2005;87(7):1430-7.

8. Hernigou P, Beaujean F. Treatment of osteonecrosis with autologous bone marrow grafting. Clin Orthop Relat Res. 2002(405):14-23.

9. Vives J, Mirabel C. Multipotent Mesenchymal Stromal Cells From Bone Marrow for Current and Potential Clinical Applications. In: Reis RL, editor. Encyclopedia of Tissue Engineering and Regenerative Medicine. Oxford: Academic Press; 2019. p. 503-12.

10. Oliver-Vila I, Coca MI, Grau-Vorster M, Pujals-Fonts N, Caminal M, Casamayor-Genesca A, et al. Evaluation of a cell-banking strategy for the production of clinical grade mesenchymal stromal cells from Wharton's jelly. Cytotherapy. 2016;18(1):25-35.

11. Codinach M, Blanco M, Ortega I, Lloret M, Reales L, Coca MI, et al. Design and validation of a consistent and reproducible manufacture process for the production of clinical-grade bone marrowderived multipotent mesenchymal stromal cells. Cytotherapy. 2016;18(9):1197-208.

12. Caminal M, Peris D, Fonseca C, Barrachina J, Codina D, Rabanal RM, et al. Cartilage resurfacing potential of PLGA scaffolds loaded with autologous cells from cartilage, fat, and bone marrow in an ovine model of osteochondral focal defect. Cytotechnology. 2016;68(4):907-19.

13. Mirabel C, Puente-Massaguer E, Del Mazo-Barbara A, Reyes B, Morton P, Gòdia F, et al. Stability enhancement of clinical grade multipotent mesenchymal stromal cell-based products. J Transl Med. 2018;16(1):291.

14. Cash JM, Remmers EF, Goldmuntz EA, Crofford LJ, Zha H, Hansen CT, et al. Genetic mapping of the athymic nude (RNU) locus in the rat to a region on chromosome 10. Mamm Genome. 1993;4(1):3742.

15. Zachos TA, Bertone AL, Wassenaar PA, Weisbrode SE. Rodent models for the study of articular fracture healing. J Invest Surg. 2007;20(2):87-95.

16. Davies G, Grant AG, Duke D, Hermon-Taylor J. Antibody response of nude (RNU/RNU) and hairy $(\mathrm{RNU} /+)$ rats to circulating cell surface components from human pancreatic cancer xenografts. $\mathrm{Br} \mathrm{J}$ Cancer. 1983;48(2):239-45. 
17. Rolstad B. The athymic nude rat: an animal experimental model to reveal novel aspects of innate immune responses? Immunol Rev. 2001;184:136-44.

18. Vishnu Priya M, Sivshanmugam A, Boccaccini AR, Goudouri OM, Sun W, Hwang N, et al. Injectable osteogenic and angiogenic nanocomposite hydrogels for irregular bone defects. Biomed Mater. 2016;11(3):035017.

19. Panwar A, Tan LP. Current Status of Bioinks for Micro-Extrusion-Based 3D Bioprinting. Molecules. 2016;21(6).

20. Gopinathan J, Noh I. Recent trends in bioinks for 3D printing. Biomater Res. 2018;22:11.

21. Dominici M, Le Blanc K, Mueller I, Slaper-Cortenbach I, Marini F, Krause D, et al. Minimal criteria for defining multipotent mesenchymal stromal cells. The International Society for Cellular Therapy position statement. Cytotherapy. 2006;8(4):315-7.

22. Codinach M, Blanco M, Ortega I, Lloret M, Reales L, Coca MI, et al. Design and validation of a consistent and reproducible manufacture process for the production of clinical-grade bone marrowderived multipotent mesenchymal stromal cells. Cytotherapy. 2016;18(9):1197-208.

23. Mendicino M, Bailey AM, Wonnacott K, Puri RK, Bauer SR. MSC-based product characterization for clinical trials: an FDA perspective. Cell Stem Cell. 2014;14(2):141-5.

24. Dighe PA, Viswanathan P, Mruthunjaya AK, Seetharam RN. Effect of bFGF on HLA-DR expression of human bone marrow-derived mesenchymal stem cells. J Stem Cells. 2013;8(1):43-57.

25. Grau-Vorster M, Rodríguez L, Torrents-Zapata S, Vivas D, Codinach M, Blanco M, et al. Levels of IL$17 F$ and IL-33 correlate with HLA-DR activation in clinical-grade human bone marrow-derived multipotent mesenchymal stromal cell expansion cultures. Cytotherapy. 2019;21(1):32-40.

26. Grau-Vorster M, Laitinen A, Nystedt J, Vives J. HLA-DR expression in clinical-grade bone marrowderived multipotent mesenchymal stromal cells: a two-site study. Stem Cell Res Ther. 2019;10(1):164.

27. Matoba S, Tatsumi T, Murohara T, Imaizumi T, Katsuda Y, Ito M, et al. Long-term clinical outcome after intramuscular implantation of bone marrow mononuclear cells (Therapeutic Angiogenesis by Cell Transplantation [TACT] trial) in patients with chronic limb ischemia. Am Heart J. 2008;156(5):1010-8.

28. Korf-Klingebiel M, Kempf T, Sauer T, Brinkmann E, Fischer P, Meyer GP, et al. Bone marrow cells are a rich source of growth factors and cytokines: implications for cell therapy trials after myocardial infarction. Eur Heart J. 2008;29(23):2851-8.

29. Friedenstein AJ, Chailakhyan RK, Gerasimov UV. Bone marrow osteogenic stem cells: in vitro cultivation and transplantation in diffusion chambers. Cell Tissue Kinet. 1987;20(3):263-72.

30. Prockop DJ. Marrow stromal cells as stem cells for nonhematopoietic tissues. Science. 1997;276(5309):71-4.

31. Pittenger MF, Mackay AM, Beck SC, Jaiswal RK, Douglas R, Mosca JD, et al. Multilineage potential of adult human mesenchymal stem cells. Science. 1999;284(5411):143-7. 
32. Buchta C, Dettke M, Funovics PT, Hocker P, Knobl P, Macher M, et al. Fibrin sealant produced by the CryoSeal FS System: product chemistry, material properties and possible preparation in the autologous preoperative setting. Vox Sang. 2004;86(4):257-62.

33. Noori A, Ashrafi SJ, Vaez-Ghaemi R, Hatamian-Zaremi A, Webster TJ. A review of fibrin and fibrin composites for bone tissue engineering. Int J Nanomedicine. 2017;12:4937-61.

34. Mankad PS, Codispoti M. The role of fibrin sealants in hemostasis. Am J Surg. 2001;182(2 Suppl):21S-8S.

35. Amrani DL, Diorio JP, Delmotte Y. Wound healing. Role of commercial fibrin sealants. Ann N Y Acad Sci. 2001;936:566-79.

36. Carless PA, Anthony DM, Henry DA. Systematic review of the use of fibrin sealant to minimize perioperative allogeneic blood transfusion. Br J Surg. 2002;89(6):695-703.

37. Currie LJ, Sharpe JR, Martin R. The use of fibrin glue in skin grafts and tissue-engineered skin replacements: a review. Plast Reconstr Surg. 2001;108(6):1713-26.

38. Liu G, Li Y, Sun J, Zhou H, Zhang W, Cui L, et al. In vitro and in vivo evaluation of osteogenesis of human umbilical cord blood-derived mesenchymal stem cells on partially demineralized bone matrix. Tissue Eng Part A. 2010;16(3):971-82.

39. Seebach E, Freischmidt H, Holschbach J, Fellenberg J, Richter W. Mesenchymal stroma cells trigger early attraction of M1 macrophages and endothelial cells into fibrin hydrogels, stimulating long bone healing without long-term engraftment. Acta Biomater. 2014;10(11):4730-41.

40. Yamada Y, Ueda M, Naiki T, Takahashi M, Hata K, Nagasaka T. Autogenous injectable bone for regeneration with mesenchymal stem cells and platelet-rich plasma: tissue-engineered bone regeneration. Tissue Eng. 2004;10(5-6):955-64.

41. Yamada Y, Nakamura S, Ito K, Umemura E, Hara K, Nagasaka T, et al. Injectable bone tissue engineering using expanded mesenchymal stem cells. Stem Cells. 2013;31(3):572-80.

42. Yamada Y, Nakamura S, Ito K, Kohgo T, Hibi H, Nagasaka T, et al. Injectable tissue-engineered bone using autogenous bone marrow-derived stromal cells for maxillary sinus augmentation: clinical application report from a 2-6-year follow-up. Tissue Eng Part A. 2008;14(10):1699-707.

43. Kargozar S, Mozafari M, Hashemian SJ, Brouki Milan P, Hamzehlou S, Soleimani M, et al. Osteogenic potential of stem cells-seeded bioactive nanocomposite scaffolds: A comparative study between human mesenchymal stem cells derived from bone, umbilical cord Wharton's jelly, and adipose tissue. J Biomed Mater Res B Appl Biomater. 2018;106(1):61-72.

44. Shimizu T, Akahane M, Morita Y, Omokawa S, Nakano K, Kira T, et al. The regeneration and augmentation of bone with injectable osteogenic cell sheet in a rat critical fracture healing model. Injury. 2015;46(8):1457-64.

45. Ma D, Zhong C, Yao H, Liu Y, Chen F, Li J, et al. Engineering injectable bone using bone marrow stromal cell aggregates. Stem Cells Dev. 2011;20(6):989-99.

\section{Figures}




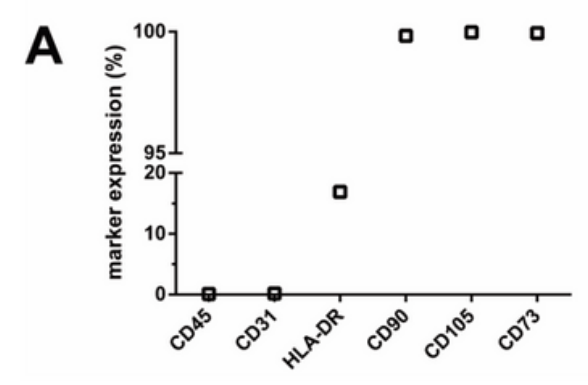

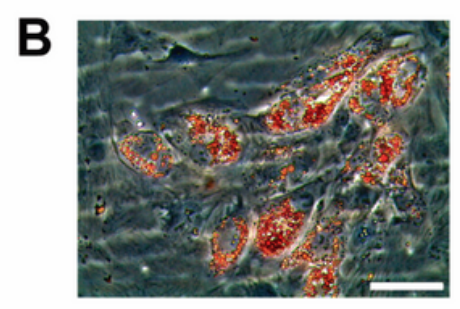

Oil Red O

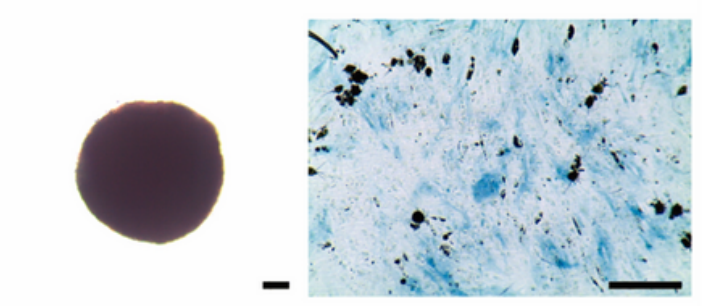

Safranin 0
ALP

\section{Figure 1}

Characteristics of multipotent Mesenchymal Stromal Cells derived from bone marrow. BM-MSC typically lacked the expression of CD31 and CD45 surface markers, whereas they readily expressed CD73, CD 90 and CD105. HLA-DR expression varied from batch to batch, but was always lower than $20 \%$ in accordance with product specifications (A). The cell line illustrated in this Figure corresponds to the one used in the in vivo study. BM-MSC also displayed differentiation potential into the adipogenic, chondrogenic and osteogenic lineages (B). Specific stainings were performed in order to determine lipidic vacuolae in adipocytes (using Oil Red $O$ stain), presence of proteoglycans in chondrogenic micromasses (using Safranin O stain), and alkaline phosphatase (ALP) activity in osteoblasts. Scale bars $=200 \mu \mathrm{m}$.

\section{Figure 2}

Stability study in fibrinogen. Cell viability was maintained above $70 \%$ along the study time (up to $48 \mathrm{~h}$ ) (A); Surface marker expression stayed consistent at the $24 \mathrm{~h}$ time point (B); Despite of cells remaining viable for 48 hours, they maintained the capacity to attach to plastic and proliferate normally only during the first $24 \mathrm{~h}$ (C); MSC taken at the $24 \mathrm{~h}$ time point still retained their osteogenic potential when subjected to osteogenic differentiation in vitro, as demonstrated by alkaline phosphatase (ALP) activity at day 8 in osteogenic inducing conditions (at two magnifications) compared to negative control stained at day 0 (top) (D). Scale bars $=200 \mu \mathrm{m}$.

\section{Figure 3}

In vivo studies using different formulation of tissue engineering products in athymic mice. Histological assessment of cylindrical constructs evidenced the presence of bone particles, whereas cells were only present in the MNC and BM-MSC groups (A). No adverse effects were observed after treatment and mean body weight gain increased steadily along the course of the study (B). Size of constructs measured at 2 months post-administration were significantly bigger in BM-MSC group compared to acellular control $(\mathrm{p}=$ 0.0191) (C). Eosinophilic islands of osteoid (arrows) were seen in all three experimental groups (D). * bone powder particles. 


\section{Supplementary Files}

This is a list of supplementary files associated with this preprint. Click to download.

- SupplementalMaterial.docx 